\title{
The presence and effect of endocrine disruptors on reproductive organs of fish in a reservoir used for aquiculture
}

\author{
L. S. Shore ${ }^{1} \&$ M. Gophen ${ }^{2}$ \\ ${ }^{1}$ Kimron Veterinary Institute, Israel \\ ${ }^{2}$ Migal Technologies, Israel
}

\begin{abstract}
A reservoir receiving some sewage water from an urban area, in addition to fresh water sources, was used for raising three species of fish. Prior to the introduction of the fish, the reservoir water contained appreciable amounts of testosterone, estrogen, ethinylestradiol and medroxyprogesterone. After introduction of the fish the level of hormones and drugs were reduced to nearly non-detectable levels while in a control reservoir without fish, the levels of the compounds remained constant. Of the three species studied, after eight months only the female carp developed gonads, which were small for body size. Observations suggest that the fish absorb the hormones and drugs in the early growing season and this has a negative effect on their reproductive development. Keywords: endocrine disrupters, ethinylestradiol, gonadal atrophy, carp, tilapia.
\end{abstract}

\section{Introduction}

Household, industrial and agricultural (recycled effluents) water sources are liable to contain Endocrine Disrupting Agents (EDAs). The EDAs are a heterologous group which can influence the endocrine system of various organisms [5] and to cause endocrine disruption in the parent organism or its offspring. In particular, chemicals that bind to the receptor of the natural hormone can mimic or depress the actions of the natural ligand. These compounds have been demonstrated to affect wildlife and domestic animals but their effects in humans are not well documented $[5,8,9]$. In the last two decades, there has been an increased awareness of the effects of these compounds on animals and man and this has been reflected in scientific publications as well as 
the media in general. This heterogenic group of EDAs contains many compounds with estrogenic actions (1) steroidal hormones (e.g. estrone, estradiol, testosterone) from animal (wildlife or domestic) or human sources. (2) Anthropogenic compounds (industrial effluent, drugs). (3) Mycoestrogens from Fusarium sp. and (4) Phytoestrogens, a group of non-steroidal compounds with estrogenic activity found naturally in plants.

\subsection{Source of environmental hormones in the Jordan River catchment area}

We have previously reported on the presence of natural and synthetic steroids (testosterone, estrone, estradiol, ethinylestradiol) in the catchments of the Jordan River $[1,10]$. The major sources of the hormones were shown to be runoff from cattle pasture and effluent from aquaculture or sewage water treatment (SWT) ponds. The hormonal profile was characteristic of each source, e.g. the presence of ethinylestradiol was indicative of SWT pond effluent. In SWT ponds, the concentrations of estrogen and testosterone can reach levels of hundreds of nanograms/liter [9].

\subsection{Impact of EDAs on fish}

EDAs are well documented to affect reproduction in fish [4]. In particular the effects of sewage water plant effluent on intersex and sexual organs are well documented [12]. The most likely EDC causing these effects is ethinylestradiol, a synthetic steroid found in birth control pills, although other EDAs have been suggested $[4,7]$.

\section{Materials and methods}

\subsection{Site description}

The reservoir held $5.6 \mathrm{mcu}^{3}$ over area of 100 acres and a depth of $15 \mathrm{~m}$. The reservoir received water from three sources: sewage effluent from an urban area of about 8000 , excess water flow from a nearby artificial lake and Jordan River water from the western canal. The water was use to raise about 400 tons of fish. The limonological properties of the reservoir have been described in detail [6].

Samples were taken on 16.02.05 before fish were introduced and 04.05.05, 04.08.05 and 19.11.05 representing 1, 5 and 8 months after the introduction. Samples were taken at depths of 1, 3 and $6 \mathrm{~m}$ except on the final sampling before harvesting when the depth was only $0.8 \mathrm{~m}$. Samples were taken from a control reservoir without fish on the same dates.

\subsection{Measurements of steroids and pharmaceuticals}

One liter aliquots of water were extracted on C-18 maxi-extraction columns (Mega BE-C18 1 gm, 6 ml PN 12256001 Varian, Middleburg, The Netherlands) as previously described $[1,10]$. Testosterone and estrogen were measured by 
radioimmunoassay $[1,10]$ Medroxyprogesterone, ethinylestradiol, androstenedione and estriol were measured using commercial ELISA kits (DRG GmbH, Marburg, Germany). The ELISA kits for determination of benzodiazapines and barbiturates were only qualitative.

\subsection{Histology}

Gonads were placed in $10 \%$ buffered formalin and slides prepared by the Dept. of Pathology at the Kimron Veterinary Institute. Gonads were evaluated according to Degani et al. [2,3].

\section{Results}

\subsection{Natural steroids}

The natural steroids, testosterone, estrogen (estradiol and estrone), androstenedione and estriol were present in the reservoir prior to introduction of the fish (Table 1). After one month there was a decline in the concentrations of testosterone, estrogen and androstenedione, which then rose towards maturation. Estriol, which only comes from human sources (pregnant women), was only present before the fish were introduced.

Table 1: $\quad$ Natural hormone concentrations in $\mathrm{ng} / \mathrm{l}$ in reservoir water.

\begin{tabular}{|l|c|c|c|c|}
\hline & $\begin{array}{c}\text { Testo- } \\
\text { sterone }\end{array}$ & Estrogen & $\begin{array}{c}\text { Androstene- } \\
\text { dione }\end{array}$ & Estriol \\
\hline $\begin{array}{l}\text { Before introduction } \\
\text { of fish }\end{array}$ & 4.13 & 4.21 & 3.00 & 1.43 \\
\hline One month after & 2.37 & 0.97 & 1.62 & $<0.1$ \\
\hline Five months after & 3.75 & 2.20 & 4.67 & $<0.1$ \\
\hline Eight months after & 5.73 & 7.07 & 18.23 & $<0.1$ \\
\hline
\end{tabular}

\subsection{Pharmaceuticals}

Prior to introduction of the fish, the reservoir was found to contain appreciable amounts of ethinylestradiol, medroxyprogesterone (both components of contraceptive pills); and benzodiazepines but was negative for barbiturates (Table 2). After three months in the presence of the fish the levels of these compounds were essential non-detectable $(<0.5 \mathrm{ng} / \mathrm{l})$. In contrast, a control reservoir without fish, the level of medroxyprogesterone and ethinylestradiol remained between 1.3 and $1.7 \mathrm{ng} / \mathrm{l}$ during the same time period.

These results indicate that there was a decrease in the pharmaceutical compounds, apparently due to absorption by the fish. On the other hand the natural steroids increased as the fish produced the gonadal steroids. 
Table 2: $\quad$ Pharmaceutical concentrations in $n g / 1$ in reservoir water.

\begin{tabular}{|l|c|c|c|}
\hline & $\begin{array}{c}\text { Ethinyl- } \\
\text { estradiol }\end{array}$ & $\begin{array}{l}\text { Medroxy- } \\
\text { progesterone }\end{array}$ & $\begin{array}{l}\text { Benzo- } \\
\text { diazepenes }\end{array}$ \\
\hline $\begin{array}{l}\text { Before introduction } \\
\text { of fish }\end{array}$ & 1.43 & 0.54 & Weak \\
\hline One month after & 1.20 & 0.50 & Negative \\
\hline Three months after & $<0.5$ & $<0.5$ & Negative \\
\hline Eight months after & 0.57 & $<0.5$ & Negative \\
\hline
\end{tabular}

\subsection{Effect on fish gonadal development}

There were three species of fish in the reservoir. The Tilapia had been treated with methyltestosterone so no ovaries were expected. However the fish should have had masculine gonads, which were absent. The mullet usually take two years or three years to mature so no gonads were expected in the mullet. However the carp should have had gonads weighing about 800 grams at eight months and the ratio of the GSI should have been in the order of $5 \%$. We found that the GSI in the females was between 0.4 to $3 \%$ and in the males, the testes were very small, in the order of $200 \mathrm{mg}$. Histological examination of the ovaries indicated the ovaries were fully matured and there was no evidence of intersex. The male testes were too small for histological analysis.

\section{Discussion}

The effects of ethinylestradiol on fish reproductive organs in controlled experiments have been well documented and it is the probable agonist present in SWTP effluent that is responsible for the widespread intersex in fish in English rivers [12]. However, the present report would the first documenting gonadal atrophy by exposure to SWTP effluent in a commercial aquaculture pond. Interesting, the brief exposure to EDAs for only one month shortly after hatching affected the gonads at maturity.

\section{Acknowledgement}

This work was supported by a grant from the Israel Ministry of the Environment.

\section{References}

[1] Barel-Cohen, K., Shore, L.S., Shemesh, M., Wenzel, A., Mueller, J. \& Kronfeld-Schor, N., Monitoring of natural and synthetic hormones in a polluted river. Journal of Environmental Management, 78, 16-23, 2005.

[2] Degani, G, Boker. R \& Jackson. K., Growth hormone, gonad development, and steroid levels in female carp. Comparative Biochemistry and Physiology C: Pharmacology, Toxicology \& Endocrinology, 115(2), pp. 433-430, 1998. 
[3] Degani, G., Boker, R. \& Jackson, K., Growth hormone, sexual maturity and steroids in male carp (Cyprinus carpio). Comparative Biochemistry \& Physiology C: Pharmacology, Toxicology \& Endocrinology, 120, pp. 433430, 1998.

[4] Lange, R., Hutchinson, T.H., Croudace, C.P. \& Siegmund, F., Effects of the synthetic estrogen 17 alpha-ethinylestradiol on the life-cycle of the fathead minnow (Pimephales promelas). Environmental Toxicology \& Chemistry, 20, pp.1216-1227. 2001.

[5] Lintelmann, L., Katayama, A., Kurihara, N., Shore, L. \& Wenzel, A., Endocrine disruptors in the environment (IUPAC Technical Report). Pure \& Applied Chemistry, 75, pp. 631-681. 2003.

[6] Milstein, A., Zoran, M. \& Krembeck, H.J., Seasonal stratification in fish culture and irrigation reservoirs: potential dangers for fish culture. Aquaculture International, 3, pp. 1-7. 1995.

[7] Panter, G.H., Thompson R.S. \& Sumpter J.P., Adverse reproductive effects in male fathead minnows (Pimephales promelas) exposed to environmentally relevant concentrations of the natural oestrogens, oestradiol and oestrone. Aquatic Toxicology, 42, pp. 243-253, 1998.

[8] Shemesh, M. \& Shore, L.S., Non-steroidal oestrogens of dietary origin: Activity, distribution and mechanism of action. Israel Journal of Veterinary Medicine, 43, pp. 192-197, 1987.

[9] Shore, L.S., Gurevich, M. \& Shemesh, M., Estrogen as an environmental pollutant. Bulletin of Environmental Contamination \& Toxicology, 51, pp.361-366. 1993.

[10] Shore, L.S. Reichman, O., Shemesh, M., Wenzel, A. \& Litaor, M., Washout of accumulated testosterone in a watershed. Science of the Total Environment, 332, pp. 193-202, 2004.

[11] Shore, L.S. \& Shemesh, M., Naturally Produced Steroid Hormones and their Release into the Environment. Pure \& Applied Chemistry, 75 (1112), pp.1859-1871, 2003.

[12] Tyler, C.R. \& Routledge E.J., Oestrogenic effects in fish in English rivers with evidence of their causation. Pure \& Applied Chemistry, 70(8), pp. 1795-1804, 1998. 